\title{
CRP single nucleotide polymorphism (rs1800947) and nutritional status in hemodialysis patients
}

Anna Popow ${ }^{1}$, Anna Wasińska-Krawczyk ${ }^{1}$, Bożenna Interewicz², Waldemar L. Olszewski², Jacek Manitius ${ }^{3}$, Alicja Rydzewska-Rosołowska ${ }^{4}$, Andrzej Rydzewski ${ }^{1,2}$

${ }^{1}$ Department of Internal Medicine, Nephrology and Transplantation Medicine, Centre of Postgraduate Medical Education, CSK MSWiA, Warsaw, Poland ${ }^{2}$ Department of Surgical Research and Transplantology, Medical Research Center, Polish Academy of Sciences, Warsaw, Poland

${ }^{3}$ Department of Nephrology, Hypertension and Internal Diseases, Collegium Medicum in Bydgoszcz, Nicolaus Copernicus University in Torun, Poland

${ }^{4} 2^{\text {nd }}$ Department of Nephrology and Hypertension with Dialysis Unit,

Medical University of Białystok, Białystok, Poland

Submitted: 25 April 2020

Accepted: 27 April 2020

Arch Med Sci Civil Dis 2020; 5: e35-e40

DOI: https://doi.org/10.5114/amscd.2020.95227

Copyright @ 2020 Termedia \& Banach

\section{Abstract}

Introduction: C-reactive protein (CRP) is an acute phase protein and was shown to be a predictor for all-cause and cardiovascular death in end stage renal disease patients. C-reactive protein is a member of the pentraxin family and plays a key role in the innate immune response. Several single nucleotide polymorphisms (SNP) associated with plasma CRP levels have been identified. This study aimed to evaluate the frequency of the rs1800947 polymorphism in the human CRP gene in maintenance hemodialysis (HD) patients, and to determine whether it is related to nutritional status.

Material and methods: We investigated 99 patients maintained on chronic hemodialysis (HD). 109 apparently healthy volunteers served as a control group. HD subjects were followed for 12 months. Anthropometric measurements were performed, the malnutrition-inflammation scale (MIS) score was determined, and blood samples were obtained within 1 month of enrollment and at 3 and 12 months of follow-up. rs1800947 SNP in the CRP gene was genotyped using restriction fragment length polymorphism-polymerase chain reaction.

Results: There were no significant differences in the investigated genotype frequencies between HD patients and controls. Moreover, there was no influence of genotype on anthropometric and laboratory indices of nutritional status and MIS score.

Conclusions: The results of this study indicate that the rs1800947 single nucleotide polymorphism in the CRP gene does not seem to correlate with nutritional status in hemodialysis patients.

Key words: C-reactive protein, single nucleotide polymorphism, chronic kidney disease, hemodialysis, nutritional status.

\section{Introduction}

Chronic kidney disease (CKD) represents a major global health problem. It is associated with increased morbidity and mortality mainly due to cardiovascular complications, and according to the 2015 Global Burden of Disease Study, it was the $12^{\text {th }}$ leading cause of death, leading

\author{
Corresponding author: \\ Anna Wasińska-Krawczyk MD \\ Department \\ of Internal Medicine \\ Nephrology and \\ Transplantation Medicine \\ Centre of Postgraduate \\ Medical Education \\ 99/103 Marymoncka St \\ 01-813 Warsaw, Poland \\ Fax: +48 225081218 \\ E-mail: \\ nefrologia@cskmswia.pl
}


to 1.1 million deaths worldwide each year $[1,2]$. CKD patients treated with chronic hemodialysis (HD) have the highest mortality rate within this group [3]. There is a strong association between mortality in patients who are treated with HD and their nutritional status as assessed by simple indicators [4].

Persistent low-grade inflammation has been implicated in the pathogenesis of malnutrition in HD patients, and several investigators have found that in patients maintained on chronic HD there is an association between markers of inflammation and nutritional status, cardiovascular disease and overall morbidity and mortality $[5,6]$. Up to $30 \%$ to $60 \%$ of HD patients have elevated CRP levels [7-9], which are independently inversely related to serum albumin levels and the risk of death [10]. However, causality has not been established for any specific inflammatory mediator [11].

Several cytokines have been implicated as factors that link malnutrition, accelerated atherogenesis, and excessive morbidity and mortality in end-stage renal disease (ESRD) patients maintained on HD [12], also the polymorphism in several cytokine coding genes was associated with the risk of malnutrition $[13,14]$.

C-reactive protein (CRP) belongs to the pentraxin family. It is produced in the liver and is secreted in increased amounts within $6 \mathrm{~h}$ of an acute inflammatory stimulus. Interleukin- 6 is the

Table I. Baseline characteristics of the chronic HD patients

\begin{tabular}{|lc|}
\hline Parameter & Value \\
\hline Age [years] & $61.6 \pm 13.5$ \\
\hline Gender, male, $n$ (\%) & $53(53.5)$ \\
\hline Cause of CKD, $n$ (\%): & $28(28.3)$ \\
\hline Chronic glomerulonephritis & $19(19.2)$ \\
\hline Unknown & $19(19.2)$ \\
\hline Chronic interstitial nephritis & $9(9.1)$ \\
\hline Polycystic diseases & $8(8.1)$ \\
\hline Vascular disease & $6(6.1)$ \\
\hline Amyloidosis & $10(10.1)$ \\
\hline Other & $6.4 \pm 5.5$ \\
\hline Dialysis vintage [years] & $23.3 \pm 4.0$ \\
\hline BMI [kg/m²] & $1.31 \pm 0.24$ \\
\hline Kt/V & $4.0 \pm 0.74$ \\
\hline Serum albumin [g/l] & \\
\hline Cholesterol [mg/ml] & \\
\hline
\end{tabular}

chief stimulator of the production of CRP [15]. CRP is encoded by a gene found on chromosome 1 close to the serum $A$ amyloid gene (SAA). The locus coding for CRP is polymorphic, which may influence its expression, and subsequently plasma levels. In 2000 Cao and Hegele described CRP polymorphism based on substitution of the single nucleotide in the 1059 position of the $2^{\text {nd }}$ exon (+1059G>C, rs1800947) [16]. Subsequently, several single nucleotide polymorphisms (SNP) associated with plasma CRP levels were identified [17].

Taking all this into account, we hypothesized that inflammation-related CRP gene polymorphism may contribute to nutritional status in HD patients, and in the present study we sought to determine the relative frequency of $+1059(\mathrm{G}>\mathrm{C})$ single nucleotide polymorphism in the CRP gene in patients with ESRD treated with chronic HD, and to compare that to a control population. We also assessed the relationship between specific alleles and different indices of nutritional status in HD patients.

\section{Material and methods}

\section{Subjects}

This was a multicenter longitudinal study. The study cohort consisted of 99 Caucasian patients with ESRD, maintained on chronic HD, who were recruited from 3 hemodialysis centers. HD was performed three times weekly. Dialyzers with lowflux, modified cellulose membranes were used. No major changes were made in the dialysis treatment or schedules during the follow-up period. Table I presents baseline characteristics of the study cohort.

Most of the patients were on antihypertensive drugs and phosphate binders. Dietary recommendations during the study were as follows: protein $0.8-1.0 \mathrm{~g} / \mathrm{kg}$ of ideal body mass (with at least half of the protein being of high biologic value), $30 \%$ of calories derived from fat and $62 \%$ of calories from carbohydrates.

The control group consisted of 109 apparently healthy volunteers, 46 males and 63 females, aged $46.9 \pm 17.9$ years.

\section{Study protocol}

Patients were eligible for the study if they were between the ages of 18 and 90 years, had been receiving $\mathrm{HD}$ treatment for at least 3 months before entering the study, and agreed to participation. Exclusion criteria included: diabetes mellitus, lupus erythematosus, ulcerative colitis, Crohn's disease, history of juvenile rheumatoid arthritis, recent acute inflammatory disease, history of neoplastic disease and treatment with steroids and immunosuppressive drugs. 
Blood samples for analysis of CRP, albumin, creatinine, urea, cholesterol and triglycerides were drawn before scheduled hemodialysis, as part of the routine protocol, within one month of enrollment and after 3 and 12 months. Serum was separated after centrifugation and stored at $-70^{\circ} \mathrm{C}$ until analysis.

Nutritional status was assessed using modified SGA scale (MIS) proposed by Kalantar-Zadeh et al. [18]. Each MIS component has four levels of severity from 0 (normal) to 3 (very severe). The sum of all 10 MIS components ranges from 0 to 30 , denoting the increasing degree of severity. Nutritional status was also evaluated by anthropometric measurements including: waist circumference, hip circumference, mid arm circumference (MAC), biceps skinfold thickness, triceps skinfold thickness (TSF), subscapular skinfold thickness and midarm muscle circumference (MAMC). MAMC was calculated as follows: $M A M C=$ MAC $-(3.1415 \times$ TSF $)$.

Subjects were weighed in light clothing. Weight was rounded to the nearest $0.5 \mathrm{~kg}$ and their height rounded to the nearest $0.5 \mathrm{~cm}$. Skinfold thickness (SFT) was measured using a Harpenden skinfold caliper, by trained investigators with standard technique, at the triceps, biceps and subscapular sites using defined anatomical landmarks [19]. The mean of 3 measurements at each site was calculated. The waist and hip circumference were measured to the nearest $0.5 \mathrm{~cm}$ at the umbilicus and greater trochanter.

Kt/V (a measure of "dialysis dose") was calculated according to the Daugirdas formula [20].

The local Ethics Committee approved the study protocol, and informed consent was obtained from all the patients and control subjects.

\section{Laboratory methods}

Routine laboratory parameters were measured in local hospital clinical laboratories. IL-6 concentration was determined with a Quantikine human IL-6 immunoassay kit (R\&D systems, USA).

Genomic DNA was isolated using the spin column method and a commercially available kit (QIAamp DNA Blood Mini Kit, Qiagen, Germany). Genotyping was performed after amplification of the target sequence (corresponding to nucleotides 514-1258, within $2^{\text {nd }}$ exon) using specific primers ( $F$ primer corresponding to nucleotides 514-535, and reverse corresponding to nucleotides 1239-1258) [16]. After Maelll digestion reaction products were electrophoresed in polyacrylamide gel, silver stained and scanned. Digestion of the $1059 \mathrm{G}$ allele with Maelll produced three fragments with sizes of $312 \mathrm{bp}, 233 \mathrm{bp}$ and $200 \mathrm{bp}$, whereas digestion of the 1059C allele gave rise to two fragments with sizes of $312 \mathrm{bp}$ and $433 \mathrm{bp}$.

\section{Statistical analysis}

Results are expressed as means \pm standard deviations. Because baseline CRP and IL- 6 concentrations were right skewed, they were log transformed before analysis.

Univariate statistical analysis was performed using the $\chi^{2}$ test, Fisher's exact test or Student's $t$-test as appropriate. Associations between variables were analyzed using Pearson's correlation coefficient or Spearman's rank correlation as appropriate.

In order to estimate the effect of $1059(\mathrm{G}>\mathrm{C})$ on variables of interest over the time of the study, we used the weighted generalized estimating equations (wGEE) approach [21] to account for individual patients with multiple exacerbations. Predictor variables in the model included gender, squared time of measurement, and age. Working correlation structure (autoregressive, exchangeable or unstructured) was selected using the quasi-AIC (QIC) method [22]. Results of GEE analysis are presented as estimated increase/decrease in the variable of interest from GEE multivariable analysis.

$P$-values $\leq 0.05$ were considered statistically significant. The STATA software, version 9.2 for Macintosh (Stata Corporation, College Station, TX, USA) was used for most statistical computations. Weighted GEE analyses were performed using $R$ version 3.6.1, wgeesel_1.5 package (https:// CRAN.R-project.org/package=wgeesel) [23].

\section{Results}

The demographic and laboratory characteristics of the patients are provided in Table I.

Sixteen subjects died and 16 dropped out of the study because of renal transplantation $(n=5)$, consent withdrawal $(n=9)$, new-onset diabetes mellitus $(n=1)$ and transfer to another dialysis center $(n=1)$.

There were no significant differences in the GC/ CC genotype frequencies between HD patients and controls ( $16.2 \%$ and $11.8 \%$, respectively; $p=$ $0.364)$. Fourteen patients who died had GG genotype and 2 had GC/CC genotypes ( $p=0.736$ ).

There was no difference, across the 12-month study interval, in any investigated biochemical, clinical or anthropometric parameters, between GG and GC/CC groups (Table II). "Dialysis dose" (as measured by Kt/V) was similar in both SNP groups.

CRP 1059G>C SNP was not associated with serum log CRP concentration, although male GG carriers had a non-significantly higher log CRP level than GC/CC variant carriers (coefficient estimate $\log \mathrm{CRP}=0.222$, robust $\mathrm{SE}=0.1184 ; p=0.06$ ).

Male sex was associated with higher log CRP levels (coefficient estimate $=0.299$ robust $\mathrm{SE}=$ $0.0748 ; p<0.001$ ) and log IL-6 (coefficient estimate 0.275 , robust $\mathrm{SE}=0.0966 ; p=0.004$ ) levels over 
A. Popow, A. Wasińska-Krawczyk, B. Interewicz, W.L. Olszewski, J. Manitius, A. Rydzewska-Rosołowska, A. Rydzewski

Table II. Relationship between SNP CRP and nutritional variables in HD patients

\begin{tabular}{|c|c|c|c|c|c|}
\hline Variable & Genotype & Baseline & At 3 months & At 12 months & $P$-value ${ }^{a}$ \\
\hline $\mathrm{Kt} / \mathrm{V}$ & $\begin{array}{c}\mathrm{GC} / \mathrm{CC} \\
\mathrm{GG}\end{array}$ & $\begin{array}{l}1.38 \pm 0.20 \\
1.30 \pm 0.24\end{array}$ & $\begin{array}{l}1.32 \pm 0.21 \\
1.37 \pm 0.22\end{array}$ & $\begin{array}{l}1.38 \pm 0.15 \\
1.38 \pm 0.22\end{array}$ & 0.335 \\
\hline $\mathrm{BMI}\left[\mathrm{kg} / \mathrm{m}^{2}\right]$ & $\begin{array}{c}\mathrm{GC} / \mathrm{CC} \\
\mathrm{GG}\end{array}$ & $\begin{array}{l}22.4 \pm 3.0 \\
23.5 \pm 4.1\end{array}$ & $\begin{array}{l}22.3 \pm 2.4 \\
23.5 \pm 4.3\end{array}$ & $\begin{array}{l}23.1 \pm 2.8 \\
22.7 \pm 6.3\end{array}$ & 0.664 \\
\hline Waist circumference $[\mathrm{cm}]$ & $\begin{array}{c}\mathrm{GC} / \mathrm{CC} \\
\mathrm{GG}\end{array}$ & $\begin{array}{c}84.5 \pm 9.8 \\
88.9 \pm 12.5\end{array}$ & $\begin{array}{l}84.7 \pm 10.2 \\
88.7 \pm 12.5\end{array}$ & $\begin{array}{l}88.1 \pm 11.9 \\
90.4 \pm 13.2\end{array}$ & 0.367 \\
\hline Hip circumference $[\mathrm{cm}]$ & $\begin{array}{c}\mathrm{GC} / \mathrm{CC} \\
\mathrm{GG}\end{array}$ & $\begin{array}{l}91.9 \pm 5.4 \\
93.4 \pm 7.9\end{array}$ & $\begin{array}{l}92.9 \pm 4.5 \\
93.7 \pm 8.2\end{array}$ & $\begin{array}{c}94.5 \pm 6.2 \\
92.3 \pm 14.6\end{array}$ & 0.750 \\
\hline WHR & $\begin{array}{c}\mathrm{GC} / \mathrm{CC} \\
\mathrm{GG}\end{array}$ & $\begin{array}{l}0.92 \pm 0.07 \\
0.95 \pm 0.09\end{array}$ & $\begin{array}{l}0.91 \pm 0.08 \\
0.95 \pm 0.09\end{array}$ & $\begin{array}{l}0.93 \pm 0.08 \\
1.15 \pm 1.48\end{array}$ & 0.204 \\
\hline Midarm circumference $[\mathrm{cm}]$ & $\begin{array}{c}\mathrm{GC} / \mathrm{CC} \\
\mathrm{GG}\end{array}$ & $\begin{array}{l}25.1 \pm 3.2 \\
25.8 \pm 3.6\end{array}$ & $\begin{array}{l}25.2 \pm 2.3 \\
25.5 \pm 3.6\end{array}$ & $\begin{array}{l}26.0 \pm 3.0 \\
25.3 \pm 3.9\end{array}$ & 0.869 \\
\hline Biceps skinfold [mm] & $\begin{array}{c}\mathrm{GC} / \mathrm{CC} \\
\mathrm{GG}\end{array}$ & $\begin{array}{c}8.6 \pm 4.2 \\
10.1 \pm 4.8\end{array}$ & $\begin{array}{l}9.1 \pm 4.3 \\
9.6 \pm 4.4\end{array}$ & $\begin{array}{l}10.1 \pm 5.6 \\
11.1 \pm 6.6\end{array}$ & 0.133 \\
\hline MAMC $[\mathrm{cm}]$ & $\begin{array}{c}\mathrm{GC} / \mathrm{CC} \\
\mathrm{GG}\end{array}$ & $\begin{array}{l}21.5 \pm 3.01 \\
21.3 \pm 3.12\end{array}$ & $\begin{array}{l}21.2 \pm 2.69 \\
21.3 \pm 2.95\end{array}$ & $\begin{array}{l}21.6 \pm 2.65 \\
21.0 \pm 3.18\end{array}$ & 0.391 \\
\hline Triceps skinfold $[\mathrm{mm}]$ & $\begin{array}{c}\mathrm{GC} / \mathrm{CC} \\
\mathrm{GG}\end{array}$ & $\begin{array}{l}11.6 \pm 5.7 \\
14.2 \pm 6.9\end{array}$ & $\begin{array}{l}12.9 \pm 6.7 \\
13.4 \pm 6.6\end{array}$ & $\begin{array}{l}13.8 \pm 7.7 \\
13.8 \pm 7.0\end{array}$ & 0.092 \\
\hline Subscapular skinfold [mm] & $\begin{array}{c}\mathrm{GC} / \mathrm{CC} \\
\mathrm{GG}\end{array}$ & $\begin{array}{l}13.0 \pm 6.1 \\
14.9 \pm 6.6\end{array}$ & $\begin{array}{l}13.4 \pm 4.8 \\
15.0 \pm 6.9\end{array}$ & $\begin{array}{l}14.1 \pm 6.4 \\
15.7 \pm 8.1\end{array}$ & 0.234 \\
\hline $\log$ CRP $[\mathrm{ng} / \mathrm{ml}]$ & $\begin{array}{c}\mathrm{GC} / \mathrm{CC} \\
\mathrm{GG}\end{array}$ & $\begin{array}{l}0.62 \pm 0.51 \\
0.66 \pm 0.48\end{array}$ & $\begin{array}{l}0.59 \pm 0.33 \\
0.70 \pm 0.52\end{array}$ & $\begin{array}{l}0.41 \pm 0.50 \\
0.60 \pm 0.53\end{array}$ & 0.631 \\
\hline Log IL-6 [pg/ml] & $\begin{array}{c}\mathrm{GC} / \mathrm{CC} \\
\mathrm{GG}\end{array}$ & $\begin{array}{l}0.91 \pm 0.25 \\
0.92 \pm 0.28\end{array}$ & $\begin{array}{l}0.90 \pm 0.15 \\
0.89 \pm 0.30\end{array}$ & $\begin{array}{l}0.83 \pm 0.38 \\
0.86 \pm 0.25\end{array}$ & 0.455 \\
\hline Creatinine pre-HD [mg/dl] & $\begin{array}{c}\mathrm{GC} / \mathrm{CC} \\
\mathrm{GG}\end{array}$ & $\begin{array}{l}9.3 \pm 2.0 \\
9.2 \pm 2.0\end{array}$ & $\begin{array}{l}9.4 \pm 2.3 \\
9.2 \pm 2.4\end{array}$ & $\begin{array}{l}9.9 \pm 2.3 \\
9.5 \pm 2.3\end{array}$ & 0.796 \\
\hline Serum cholesterol [mg/dl] & $\begin{array}{c}\mathrm{GC} / \mathrm{CC} \\
\mathrm{GG}\end{array}$ & $\begin{array}{l}168.8 \pm 37.5 \\
179.7 \pm 54.1\end{array}$ & $\begin{array}{l}176.6 \pm 43.4 \\
181.0 \pm 49.6\end{array}$ & $\begin{array}{l}172.4 \pm 40.3 \\
172.6 \pm 49.5\end{array}$ & 0.189 \\
\hline Triglycerides [mg/dl] & $\begin{array}{c}\mathrm{GC} / \mathrm{CC} \\
\mathrm{GG}\end{array}$ & $\begin{array}{c}164.7 \pm 79.5 \\
182.9 \pm 135.4\end{array}$ & $\begin{array}{l}138.4 \pm 76.9 \\
164.4 \pm 84.2\end{array}$ & $\begin{array}{c}181.2 \pm 94.6 \\
171.7 \pm 132.3\end{array}$ & 0.196 \\
\hline Serum protein $[g / l]$ & $\begin{array}{c}\mathrm{GC} / \mathrm{CC} \\
\mathrm{GG}\end{array}$ & $\begin{array}{l}7.3 \pm 0.9 \\
7.4 \pm 0.9\end{array}$ & $\begin{array}{l}6.9 \pm 0.6 \\
7.2 \pm 2.4\end{array}$ & $\begin{array}{l}7.1 \pm 0.9 \\
7.1 \pm 0.8\end{array}$ & 0.397 \\
\hline Serum albumin $[\mathrm{g} / \mathrm{l}]$ & $\begin{array}{c}\mathrm{GC} / \mathrm{CC} \\
\mathrm{GG}\end{array}$ & $\begin{array}{l}3.9 \pm 0.7 \\
4.1 \pm 0.8\end{array}$ & $\begin{array}{l}3.8 \pm 0.5 \\
4.0 \pm 1.6\end{array}$ & $\begin{array}{l}4.1 \pm 0.6 \\
4.2 \pm 0.5\end{array}$ & 0.205 \\
\hline $\mathrm{TIBC}[\mathrm{mg} / \mathrm{dl}]$ & $\begin{array}{c}\mathrm{GC} / \mathrm{CC} \\
\mathrm{GG}\end{array}$ & $\begin{array}{l}248.2 \pm 63.9 \\
255.3 \pm 59.6\end{array}$ & $\begin{array}{l}244.2 \pm 67.0 \\
224.1 \pm 64.0\end{array}$ & $\begin{array}{l}265.1 \pm 50.7 \\
261.3 \pm 83.8\end{array}$ & 0.885 \\
\hline MIS (median 25-75 percentile) & $\begin{array}{c}\mathrm{GC} / \mathrm{CC} \\
\mathrm{GG}\end{array}$ & $\begin{array}{c}9(5-12) \\
7.5(5-10)\end{array}$ & $\begin{array}{l}9(7-12) \\
9(7-13)\end{array}$ & $\begin{array}{l}7.5(4-10) \\
8(7-12)\end{array}$ & 0.381 \\
\hline
\end{tabular}

Values derived from weighted GEE multivariable analysis for association over 12 months of variable of interest with 1059(G>C) SNP.

12 months of the study (Figure 1), and lower levels of triglycerides (coefficient estimate -50.740 , robust $\mathrm{SE}=20.7686 ; p=0.015)$, and total cholesterol (coefficient estimate 44.565 , robust SE $=8.2751$; $p<0.001)$. Log IL-6 levels were associated with age (coefficient estimate 0.01349 , robust $\mathrm{SE}=0.0034$; $p<0.001$ ) over 12 months of the study (Figure 2).

At baseline of the study there was a positive correlation between log CRP and log IL-6 ( $r=$ 0.278 ; $p<0.0001$ ), and between both of the inflammatory markers and waist-hip ratio (WHR) $(r=0.231 ; p=0.0001$ and $r=0.191 ; p=0.002$ respectively). There was also an inverse correlation of baseline serum albumin and CRP and IL- 6 $(r=-0.279 ; p<0.0001$ and $r=-0.169 ; p=0.007$ respectively).

\section{Discussion}

The main finding of our study is that apparently there was no difference in time course in any investigated biochemical, clinical or anthropometric parameters over 12 months, between GG and GC/CC groups. As CRP SNPs are associated with serum CRP levels in the general population [24], which in turn is associated with nutritional status in CKD stage 5 patients, we were interested in whether long-term average concentration of CRP (as approximated by a 12-month period) would be affected by rs1800947 CRP SNP. 


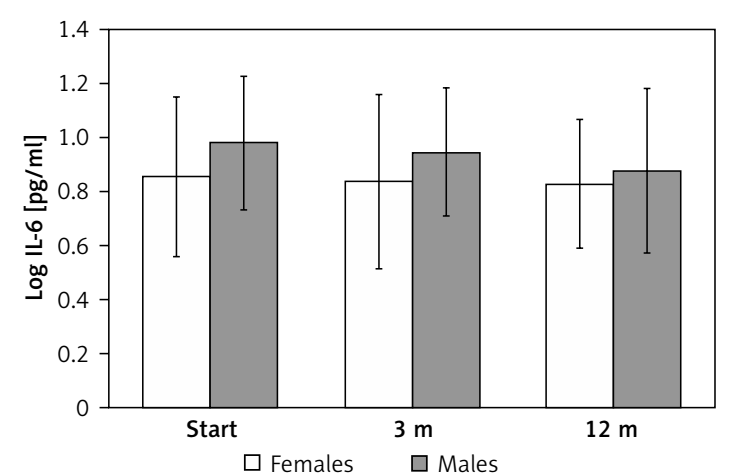

Figure 1. Log IL-6 levels in women and men over 12 months of the study $(p=0.004)$. For details see Results section

Frequency of the $\mathrm{C}$ allele (low producer) in our control group was similar to that reported by Cao and Hegele [16] for Caucasians, and did not differ significantly from the HD patient group. On the other hand, Zee and Ridker [25] found a somewhat lower frequency of that allele in a group of 700 healthy individuals in the USA. Furthermore, they additionally found that plasma CRP concentrations were significantly reduced among carriers of a $1059 \mathrm{G}>$ C polymorphism (GC/CC) as compared with non-carriers (GG) [25].

In our study CRP 1059G >C SNP was not significantly associated with serum CRP concentration. This is at variance with findings of others $[25,26]$. It probably can be explained by the low number of subjects and confounding. We observed non-significantly higher levels of CRP in male carriers of GG genotype. Interestingly, Eklund et al. found that male carriers of the +1059 C allele had significantly lower CRP concentrations than GG homozygotes. No significant difference was found in women [27].

SNPS in the CRP gene may also influence the acute phase response, which is frequently observed in the HD patient population in addition to prolonged low-intensity reaction. In fact, this was confirmed for the rs1800947 SNP in patients with acute coronary ischemia [28], acute pancreatitis [29], ischemic stroke [30], inherited depression [31] and another CRP gene variant $(+1444 C / T)$, which influenced both basal and stimulated CRP level after strenuous physical exercise and perioperatively in coronary artery bypass grafting [32].

Differently to our findings (of no association between rs1800947 SNP and anthropometric and laboratory indices of nutritional status), subjects treated with chronic HD, with high producer genotypes for other proinflammatory cytokines such as IL-6 or TNF- $\alpha$, had higher comorbidity and lower functional scores, and lower serum albumin levels [14], and the TNF- $\alpha-308$ polymorphism was reportedly associated with the risk of malnutrition inflammation syndrome (MIS) [13].

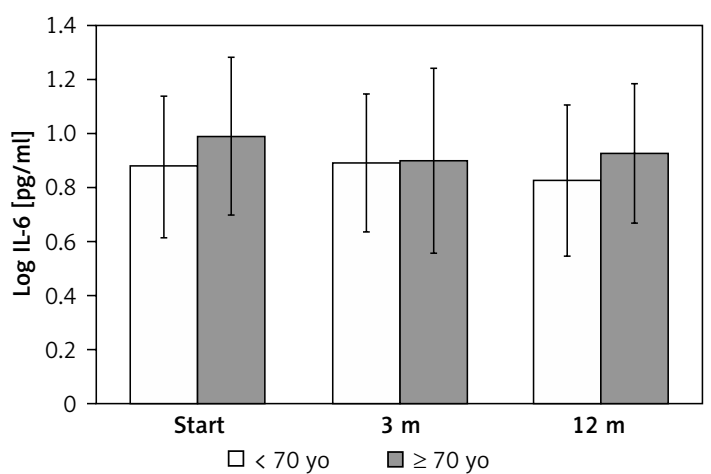

Figure 2. Log IL-6 levels in subjects younger and older than 70 years old, over 12 months of the study. For details see Results section

The so-called 'malnutrition-inflammation complex syndrome' (MICS) [33] or 'malnutrition-inflammation-atherosclerosis' syndrome [34] is the simultaneous combination of malnutrition and inflammation. MICS appears to play a central role in poor clinical outcome including the high rate of mortality and hospitalization and diminished quality of life seen in dialysis patients. MICS is also believed to be the underlying condition of the phenomenon known as "reverse epidemiology" of cardiovascular risks in these patients, where a low, and not a high, BMl or serum cholesterol is associated with poor dialysis outcome [35].

The correlation between WHR (a proxy for visceral adipose tissue mass) [36] and markers of inflammation (CRP, IL-6) suggests that central fat is important in the pathophysiology of MICS and is in agreement with others [37].

Due to the relatively short duration of the study we have not attempted to correlate actual morbidity and mortality with CRP genotype.

There are limitations of our study that merit consideration. First, and most important, is the small size of the study, which therefore may be regarded rather as hypothesis generating. Second, while our analysis focused on the impact of only one CRP polymorphism, a combination of different polymorphisms, and other genetic factors as well as environmental factors likely interact with respect to investigated parameters.

In conclusion, the investigated polymorphism does not seem to correlate with nutritional status in hemodialysis patients.

\section{Acknowledgments}

This study was supported by grant no. 3P05B02024 from the Committee for Scientific Research, Poland.

\section{Conflict of interest}

The authors declare no conflict of interest. 


\section{References}

1. Hill NR, Fatoba ST, Oke JL, et al. Global prevalence of chronic kidney disease - a systematic review and meta-analysis. PLoS One 2016; 11: e0158765.

2. GBD 2015 Mortality and Causes of Death Collaborators. Global, regional, and national life expectancy, all-cause mortality, and cause-specific mortality for 249 causes of death, 1980-2015: a systematic analysis for the Global Burden of Disease Study 2015. Lancet 2016; 388: 1459-544.

3. Naylor KL, Kim SJ, McArthur E, Garg AX, McCallum MK Knoll GA. Mortality in incident maintenance dialysis patients versus incident solid organ cancer patients: a population-based cohort. Am J Kidney Dis 2019; 73: 765-76.

4. Leavey SF, Strawderman RL, Jones CA, Port FK, Held PJ. Simple nutritional indicators as independent predictors of mortality in hemodialysis patients. Am J Kidney Dis 1998; 31: 997-1006.

5. Qureshi AR, Alvestrand A, Divino-Filho JC, et al. Inflammation, malnutrition, and cardiac disease as predictors of mortality in hemodialysis patients. J Am Soc Nephrol 2002; 13 Suppl 1: S28-36.

6. Jankowska M, Cobo G, Lindholm B, Stenvinkel P. Inflammation and protein-energy wasting in the uremic milieu. Contrib Nephrol 2017; 191: 58-71.

7. Ikizler TA, Wingard RL, Harvell J, Shyr Y, Hakim RM. Association of morbidity with markers of nutrition and inflammation in chronic hemodialysis patients: a prospective study. Kidney Int 1999; 55: 1945-51.

8. Sezer S, Ozdemir FN, Arat Z, Turan M, Haberal M. Triad of malnutrition, inflammation, and atherosclerosis in hemodialysis patients. Nephron 2002; 91: 456-62.

9. Zimmermann J, Herrlinger S, Pruy A, Metzger T, Wanner C. Inflammation enhances cardiovascular risk and mortality in hemodialysis patients. Kidney Int 1999; 55: 648-58.

10. Owen WF, Lowrie EG. C-reactive protein as an outcome predictor for maintenance hemodialysis patients. Kidney Int 1998; 54: 627-36.

11. Feldreich T, Nowak C, Fall T, et al. Circulating proteins as predictors of cardiovascular mortality in end-stage renal disease. J Nephrol 2019; 32: 111-9.

12. Bologa RM, Levine DM, Parker TS, et al. Interleukin-6 predicts hypoalbuminemia, hypocholesterolemia, and mortality in hemodialysis patients. Am J Kidney Dis 1998; 32: 107-14.

13. Sharma R, Agrawal S, Saxena A, Sharma RK. Association of IL-6, IL-10, and TNF-alpha gene polymorphism with malnutrition inflammation syndrome and survival among end stage renal disease patients. J Interferon Cytokine Res 2013; 33: 384-91.

14. Balakrishnan VS, Guo D, Rao M, et al. Cytokine gene polymorphisms in hemodialysis patients: association with comorbidity, functionality, and serum albumin. Kidney Int 2004; 65: 1449-60.

15. Gabay C, Kushner I. Acute-phase proteins and other systemic responses to inflammation. N Engl J Med 1999; 340: 448-54.

16. Cao $\mathrm{H}$, Hegele RA. Human C-reactive protein (CRP) 1059G/C polymorphism. J Hum Genet 2000; 45: 100-1.

17. https://www.ncbi.nlm.nih.gov/snp/?term=crp.

18. Kalantar-Zadeh K, Kopple JD, Block G, Humphreys MH. A malnutrition-inflammation score is correlated with morbidity and mortality in maintenance hemodialysis patients. Am J Kidney Dis 2001; 38: 1251-63.

19. Tanner JM, Whitehouse RH. The Harpenden skinfold caliper. Am J Phys Anthropol 1955; 13: 743-6.
20. Daugirdas JT. Second generation logarithmic estimates of single-pool variable volume Kt/V: an analysis of error. J Am Soc Nephrol 1993; 4: 1205-13.

21. Preisser JS, Lohman KK, Rathouz PJ. Performance of weighted estimating equations for longitudinal binary data with drop-outs missing at random. Stat Med 2002; 21: 3035-54.

22. Pan W. Akaike's information criterion in generalized estimating equations. Biometrics 2001; 57: 120-5.

23. R Core Team. R: A Language and Environment for Statistical Computing. Vienna, Austria: R Foundation for Statistical Computing, 2019.

24. Crawford DC, Sanders CL, Qin X, et al. Genetic variation is associated with C-reactive protein levels in the Third National Health and Nutrition Examination Survey. Circulation 2006; 114: 2458-65

25. Zee RY, Ridker PM. Polymorphism in the human C-reactive protein (CRP) gene, plasma concentrations of CRP, and the risk of future arterial thrombosis. Atherosclerosis 2002; 162: 217-9.

26. Dai DF, Chiang FT, Lin JL, et al. Human C-reactive protein (CRP) gene $1059 \mathrm{G}>\mathrm{C}$ polymorphism is associated with plasma CRP concentration in patients receiving coronary angiography. J Formos Med Assoc 2007; 106: 347-54.

27. Eklund C, Lehtimäki T, Hurme M. Epistatic effect of C-reactive protein (CRP) single nucleotide polymorphism (SNP) +1059 and interleukin-1B SNP +3954 on CRP concentration in healthy male blood donors. Int J Immunogenet 2005; 32: 229-32.

28. Suk Danik J, Chasman DI, Cannon CP, et al. Influence of genetic variation in the $\mathrm{C}$-reactive protein gene on the inflammatory response during and after acute coronary ischemia. Ann Hum Genet 2006; 70: 705-16.

29. Rydzewska G, Degowska M, Kierzkiewicz M, et al. Polymorphism in the human C-reactive protein (CRP) gene in acute pancreatitis. Gastroenterology 2004; 126: A85.

30. Zhu Y, Hu SC, Zheng PW, et al. Association between CPR-related genetic variants and risk of ischemic stroke: a nested case-control study. Neurol Res 2019; 41: 1090-6.

31. Wang $\mathrm{S}$, Zhong $\mathrm{H}$, Lu $\mathrm{M}$, et al. Higher serum $\mathrm{C}$ reactive protein determined $C$ reactive protein single-nucleotide polymorphisms are involved in inherited depression. Psychiatry Investig 2018; 15: 824-8.

32. Brull DJ, Serrano N, Zito F, et al. Human CRP gene polymorphism influences CRP levels: implications for the prediction and pathogenesis of coronary heart disease. Arterioscler Thromb Vasc Biol 2003; 23: 2063-9.

33. Kalantar-Zadeh K, Ikizler TA, Block G, Avram MM, Kopple JD. Malnutrition-inflammation complex syndrome in dialysis patients: causes and consequences. Am J Kidney Dis 2003; 42: 864-81.

34. Stenvinkel P, Heimbürger O, Paultre F, et al. Strong association between malnutrition, inflammation, and atherosclerosis in chronic renal failure. Kidney Int 1999; 55: 1899-911.

35. Kalantar-Zadeh K, Block G, Humphreys MH, Kopple JD. Reverse epidemiology of cardiovascular risk factors in maintenance dialysis patients. Kidney Int 2003; 63: 793-808.

36. Swainson MG, Batterham AM, Tsakirides C, Rutherford $\mathrm{ZH}$, Hind K. Prediction of whole-body fat percentage and visceral adipose tissue mass from five anthropometric variables. PLoS One 2017; 12: e0177175.

37. Delgado C, Chertow GM, Kaysen GA, et al. Associations of body mass index and body fat with markers of inflammation and nutrition among patients receiving hemodialysis. Am J Kidney Dis 2017; 70: 817-25. 